\title{
El urbanita tecno-nómada y la Ciudad excluyente
}

\section{The techno-nomadic urbanite and the excluding city}

Rubén Arturo Cacsire Grimaldos

Universidad Politécnica de Madrid, España

racacsire@unap.edu.pe

https://orcid.org/0000-0003-1063-3023

Angelique Trachana

Universidad Politécnica de Madrid, España

angelique.trachana@upm.es

https://orcid.org/0000-0002-4398-4543 


\title{
Resumen
}

Partiendo de un análisis de la evolución de la ciudad industrial a la ciudad posindustrial en la era global y desde una perspectiva interdisciplinar, se trata de describir y argumentar cómo la vida urbana se desprende de las estructuras sólidas y estables de la ciudad; demostrar la eminente separación entre lo vivido y lo construido. Las diferentes movilidades y la inestabilidad en todos los aspectos de la vida, desde lo familiar, privado e íntimo a lo relacional, público y laboral las relaciones se vuelven "líquidas" en la gran ciudad y se van perdiendo los referentes estables. Las nuevas tecnologías digitales y las comunicaciones promueven la vida móvil. El nuevo urbanita tecno-nómada, categoría que incluye el inmigrante precario, el turista, el habitante que se convierte en turista en su propia ciudad y todo un elenco de especies urbanas que buscan oportunidades en la gran ciudad, experimentan el desarraigo, el individualismo y las instituciones debilitadas. En un mundo conectado a distancia a las redes trasnacionales, las grandes ciudades desconectadas interiormente fomentan grandes rupturas, discontinuidades y exclusiones. El método de abordaje de este estudio enfoca el "urbanita" en vez del habitual enfoque del urbanismo en un emergente contexto socio tecnológico y trata de definir cómo se construyen las subjetividades.

Palabras clave: ciudad global; migraciones, tecnología digital; urbanita; nómada; precariedad

\begin{abstract}
This study analyzes the evolution from the industrial city to the post-industrial city in the global era from an interdisciplinary perspective. It describes and argues how urban life is separated from the solid and stable structures of the city in order to demonstrate the eminent break between what is lived and what is built. The different mobilities and instability in all aspects of life, from the familiar, private and intimate to the relational, public and working relationships become "liquid" in the big city and stable references are being lost. The New digital technologies and communications promote the mobile life. The new techno-nomadic urbanite as a category that includes the precarious immigrant, the tourist, the inhabitant who becomes a tourist in his own city, and a whole cast of urban species that seek opportunities in the big city, experiment the uprooted individualism and the weakened institutions. In a world remotely connected to transnational networks, the big cities, internally disconnected, foster large breaks, discontinuities and exclusions. The approach method of this study focuses on the "urbanite" instead of the usual approach of urbanism in an emerging socio-technological context and aims to define how subjectivities are constructed.
\end{abstract}

Key words: global city; migrations; digital technology; urbanite; nomad; precariousness

\section{Para citar este artículo / To cite this article:}

GALIMBERTI, C. El urbanita tecno-nómada y la Ciudad excluyente. En: [i2] Investigación e Innovación en Arquitectura y Territorio [en línea], 2020, Vol. 8, Núm. 2. ISSN: 2341-0515. https://doi.org/10.14198/i2.2020.2.02

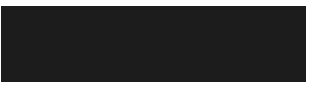




\section{Introducción. Entre lo construido y lo vivido}

La ciudad no es simplemente un mecanismo físico y una construcción artificial, sino el proceso vital de la gente que la compone; es un producto de la naturaleza, y en particular de la naturaleza humana. Una ciudad, como reza el cliché, es su gente (Park, 1969: 91).

Sin embargo, desde mediados del siglo pasado y más acentuadamente en el presente, se distingue una, cada vez más, acentuada brecha entre los lugares construidos y las personas que los habitan, entre lo construido y lo vivido. "La indiferencia respecto a la ciudad física no hace más que empeorar el problema de la desconexión social” (Sennett, 2019: 95)". Según Sennett, el homo faber en la gran ciudad se ha convertido en homo urbanus. El homo faber como eminente constructor de la ciudad, ha sido reemplazado por los planificadores y urbanistas quienes, al no considerar a este actor urbano como razón principal de su ejercicio, y en lugar de eso se basan en la rentabilidad del capital, la aplicación de altas tecnologías y la estética formal consumista, sólo están conduciendo a la ruptura entre lo construido y lo social. Es más, al considerar el ciudadano-usuario, lo hacen desde la óptica de un urbanita tradicional con referentes estables, sin pensar en que las nuevas condiciones establecidas por la tecnología digital, la generación $\mathrm{Z}$, la migración global, las diferentes movilidades y el nomadismo urbano, fundamentan la inestabilidad como caldo de cultivo del neo-urbanita del siglo XXI.

El mundo de la tecnología actual trata de vencer las restricciones espacio-temporales, acelerando la vida cotidiana y transformando los seres humanos de sedentarios a más radicalmente "nómadas". "Tal incremento de la movilidad no podría dejar de tener influencia sobre la forma en que se define la identidad de los individuos y de los grupos sociales" (Hiernaux-Nicolas, 2014: 42). Más que de identidades culturales y de arraigo, se trata de la identidad del nuevo "urbanita-móvil" que experimenta la ciudad como "nómada urbano". La experiencia de este nuevo personaje en la ciudad de hoy se desliga cada vez más del lugar físico que lo contiene, lo construido, y su identidad se moldea en un espacio social-tecnológico donde se relaciona.

Si bien puede contribuir al conocimiento el plantear la disyuntiva entre la ciudad concebida (planificada y administrada) y la ciudad practicada (percibida, vivida, usada, ensoñada) o "lo social en acción" como diría Delgado (2007: 14), "la sociedad que producen los urbanitas, la manera que éstos tienen de gastar los espacios que utilizan y al mismo tiempo crean", son los practicantes de la ciudad quienes constantemente se desentienden de las directrices diseñadas. El hecho de desentenderse que podría entenderse como libertad de practicar y experimentar cualquier parte de la ciudad, en la realidad ocurre en el sentido contrario: que haya espacios a los que no se tiene acceso o que no se puedan practicar; espacios exclusivos (Santos, 2000), "áreas cerradas cada vez más amplias de servicios exclusivos, seguridad privada, apropiación privada de bienes naturales" (Torres, 2009: 204) y espacios públicos y un largo etc.

La comprensión de la ciudad contemporánea requiere conocer su paso de ciudad industrial (ligada a los recursos naturales) a la ciudad posindustrial de servicios. Los primeros planificadores de ciudades en crecimiento, primero en Europa y posteriormente en Norteamérica, en el siglo XIX, trataban de conectar lo vivido con lo 
construido. El Barón Haussmann en París, Ildefons Cerdá en Barcelona y Frederick Law Olmsted en Nueva York planificaron la ciudad continua y compacta, de extensión horizontal, multifuncional, compleja y mucho más humana por la amalgama de clases de personas, de usos y funciones, espacio público y vida social, por la agregación, la superposición, el cambio, la autorregulación. Jane Jacobs (2011: 163) recordaba "las formas urbanas que surgían lentamente y por acumulación como lecciones del uso y de la experiencia”. Maffesoli (1999) piensa que su complejidad, además, la constituye a sí misma como la ciudad del "descontrol". Pues, es donde el sistema pierde más su omnipotencia, el ejercicio del control y de la vigilancia.

Pero estas relaciones complejas se han ido simplificando en el siglo XX, según el modelo de la Carta de Atenas y su insigne representante Le Corbusier. La ciudad zonificada y el espacio-tiempo planificado -según las tres ocho: 8 horas para trabajar, 8 horas para descansar y otras 8 horas de tiempo libre-, se han simplificado. El espacio público se ha simplificado en el concepto de espacio libre, abstracto, indiferenciado, supuestamente naturaleza, espacio de la libertad, y, realmente, espacio del automóvil. "La cité (lo vivido) y la ville (lo construido) se distanciaron una de otra en la manera en que los urbanistas pensaban y acometían la construcción de ciudades" (Sennett, 2019: 29).

Las ciudades globales de hoy sin límites físicos sino como zonas de influencia y las megaciudades como aglomerados urbanos y atractores de grandes poblacionales precarias, han polarizado todavía más la segmentación y han hecho aparecer en el Sur global con más virulencia los conflictos no resueltos del Norte global (Sennett, 2019; Guattari, 1996)

Factores determinantes de la metrópolis posindustrial del siglo XXI son la tecnología digital y los medios de comunicación, que han acentuado la ruptura entre lo construido y lo vivido llevando la vida urbana de los cuerpos a un continuo movimiento y las relaciones interpersonales en el entorno virtual. Las grandes metrópolis por su poder económico y cultural de influencia a escala mundial forman parte de una red de ciudades globales (Sassen, 2001), mejor dicho, de fragmentos de ciudades articulados en redes mundializadas, que son sedes con sus centros de producción lejos, en otros países. Conectadas entre sí por redes virtuales, interiormente o físicamente están desconectadas de la población que las sustenta. Pues, en sintonía con la ciudad global -dispersa, fragmentada y desconectada- se está consolidando la nueva condición nómada naturalizada del urbanita contemporáneo.

Los avances tecnológicos parece que han nivelado el mundo y reducido las distancias como se anuncia en la teoría del "mundo plano" de Friedman (2007). El "hábitat" como lugar transformado y acondicionado por el ser humano y el "habitar" asociado al lugar de residencia, la ciudad y el territorio, sufren notables mutaciones respectivamente. El habitar que da cuenta de la condición espacio-temporal del ser humano y como habitante de la ciudad, "el urbanita”, ya no sólo habita la casa sino también otros lugares, pasando de la experiencia de "estar en casa" a la experiencia de "estar como en casa" (Lindón, 2014: 58-59). 
Richard Florida (2009:28), avanza un poco más en la relación habitante-espacio del habitar anunciando la importancia del lugar, al mismo tiempo que lamenta cómo "la economía global impulsa una reducción de la cantidad de lugares". Michael Porter (2006) lo llama la "paradoja de la localización". "La ubicación sigue siendo importante. Cuanto más móvil se vuelve todo, más importante resulta la localización”.

Florida (2009: 41) plantea una imagen de picos o cumbres, de un número relativamente pequeño, como lugares que atraen el talento global y generan innovación que normalmente se exporta a las regiones que visualiza como las colinas emergentes. Estas importan y usan la innovación y la creatividad para producir bienes y servicios en las megaciudades en vías de desarrollo. Y están también los enormes valles del mundo puntiagudo, las áreas rurales y los lugares remotos que tienen una concentración demográfica y una actividad económica muy reducidas, y que están poco vinculados a la economía global.

Las grandes ciudades del siglo XXI reflejan este paisaje del mundo puntiagudo. En él se identifican los centros globales (político-financieros) consolidados con sus edificios más altos como Nueva York, Shanghái, Dubái entre otros, sus zonas emergentes o intermedias y las vastas zonas horizontales periféricas de escasa actividad económica. Esta configuración picuda de la ciudad global se constituye por núcleos de "concentración" y "atracción” para un reducido grupo de personas con talento y niveles educativos elevados frente a la enorme planicie del resto de habitantes, quienes discurren por ese plano horizontal y ejercen un movimiento pendular entre la planicie y el centro.

Para el autor, en las megarregiones y megaciudades donde migran personas con talento y habilidades de innovación, "las cumbres más elevadas que impulsan la economía mundial, crecen cada vez más, mientras que los valles que prácticamente carecen de actividad económica, languidecen en su mayoría" (Florida, 2009: 28). Estas llanuras que siguen creciendo desmesuradamente por las afluencias migratorias, fundamentalmente, se relacionan con la pobreza y las condiciones de precariedad e informalidad de las ciudades del Sur global de los países subdesarrollados del tercer mundo o en vías de desarrollo (Fig. 1). El informe Aglomeraciones más pobladas del mundo del 2019 para Latinoamérica asigna a la Ciudad de México, 22 millones, a Sao Paulo, 21 millones, a Buenos Aires, 14 millones de población. En África, Lagos de Nigeria cuenta con 17 millones, El Cairo (Egipto), con 16 millones, Johannesburgo (Sudáfrica), con 13 millones. Y en Asia, Yakarta (Indonesia) con 30 millones, Dheli (India) con 25 millones, Karachi (Pakistán) con 22 millones. En estas grandes aglomeraciones urbanas del Sur se observa in extremis la exclusión y la precariedad que, en el Norte global, en cierto modo, reproducen las personas transnacionales que constituyen hoy la amalgama que puebla las periferias urbanas y perciben su entorno como ajeno y así mismos. 


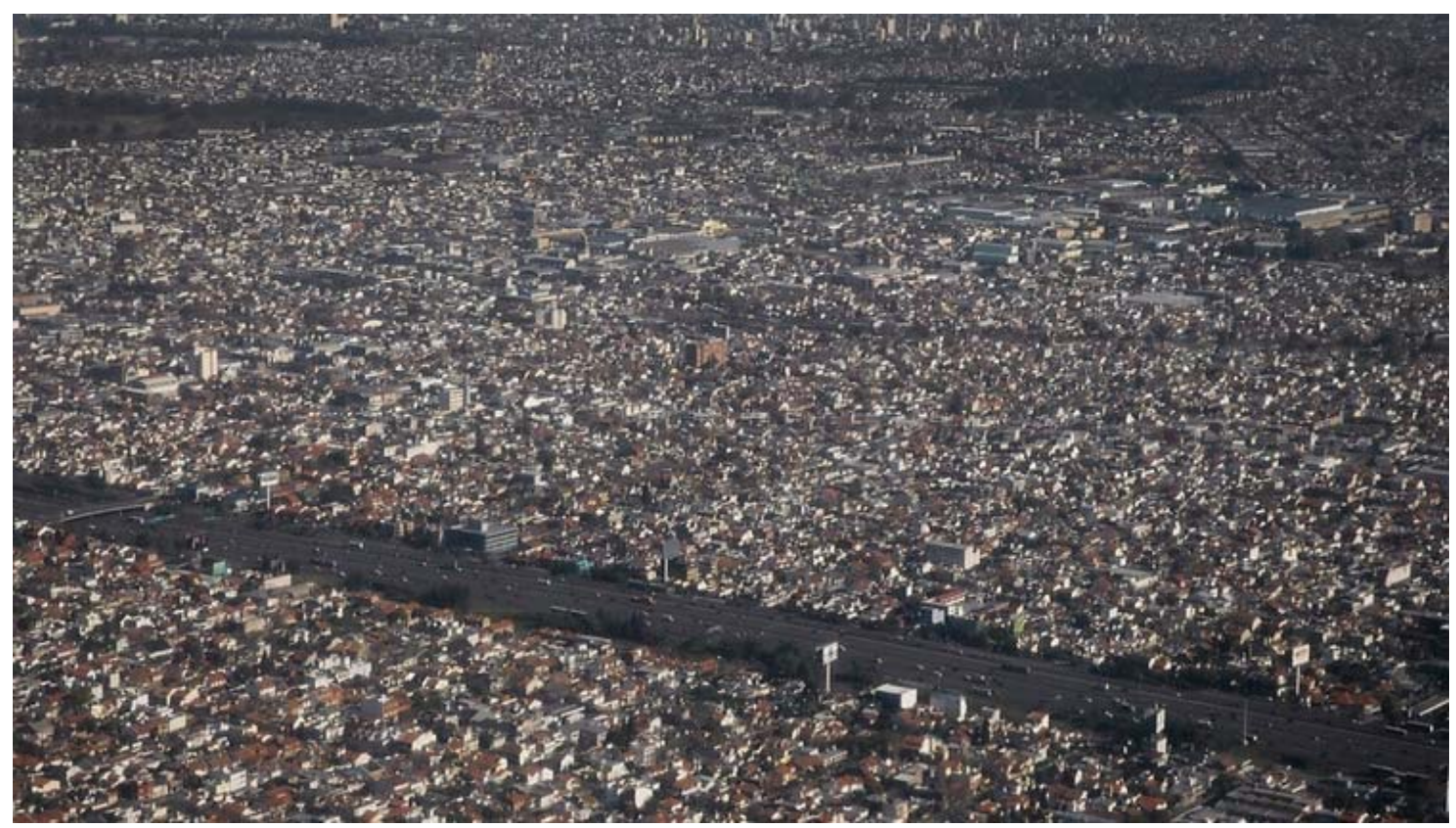

Fig. 1: Las ciudades se expanden en bajas densidades y servicios deficientes, Infobae, 2019.

\section{Ciudad vertical, ciudad inteligente frente a la ciudad compleja}

Mientras la proporción de la población mundial que vive en ciudades continúa creciendo, los rascacielos desempeñan la función de crear densas zonas donde viva y trabaje la gente. El paisaje puntiagudo, no es exclusividad de ciudades del Norte global. Ciudades que experimentaron históricamente crecimientos horizontales, han impulsado la construcción de estas megaestructuras como símbolos de su poder económico desde el principio de siglo XX, en el Norte y hace ya unas décadas también en el Sur global. Los skylines de metrópolis que superan los 300 metros se ubican en el Norte de América -Nueva York con 20 millones de habitantes, Chicago con 9 millones o Toronto con 6 millones-, en Europa -Londres alcanza los 14 millones-, en Asia y Medio Oriente -Tokio ya tiene 38 millones (Fig. 2), Shanghái con 30 millones, Singapur con 7 millones y Dubái con 4 millones-. La sobrepoblación y la densidad no es ajena a su concepción vertical, pero hay un factor simbólico fundamental asociado con la altura como desafío, poder y autoridad. Si la verticalidad se articula como imagen del poder esta imagen se enfrenta a la imagen de la horizontalidad característica de una ciudad más democrática, más igualitaria, abierta y accesible a todos. Las ciudades verticales son competitivas y la altura de sus edificios-torre, tales como The Shard de 306 metros en Londres o el BurjKhalifa de 828 metros en Dubai, las introduce en una carrera por romper records y entrar en el ranking de altura. El Skyline de la ciudad es, además, un atractivo turístico y deviene foco de atención visual en la extensa superficie ocupada y sobrepoblada, a la que domina y finalmente invisibiliza. 


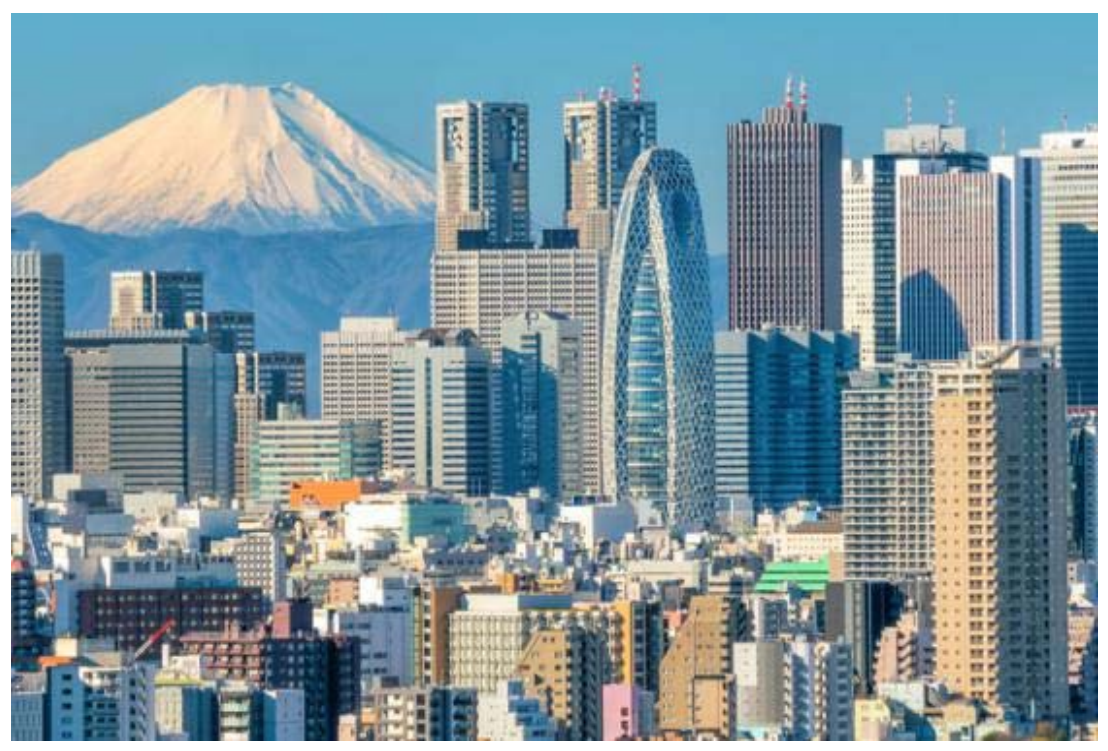

Fig. 2: Tokio, la ciudad más grande del mundo, El Comercio, 2018.

Este tipo de ciudad vertical de avanzada ingeniería estructural, se constituye en un tipo de "ciudad inteligente" gracias a las tecnologías digitales. A semejanza del Plan Voisin de Le Corbusier, las enormes torres y las grandes autopistas reflejo de la alta tecnología constructiva y la innovación del producto vehículo, es lo mecánico que reemplaza al individuo y, con lo digital, la humanidad y la sociedad quedan de lado, mientras que el poder como "control tecnológico" no solamente se identifica como un centro sino desde todos los lados.

Richard Sennett (2019: 29), identificaba tres formas de planificar la ciudad en relación al poder y la vigilancia: La cuadrícula o damero, esencial manera de control venida desde la época de los Romanos, implantada como nuevo orden de las ciudades españolas en el nuevo mundo y planteada por Ildefons Cerdá en Barcelona como una ciudad celular con espacios interiores de la cuadrícula reivindicados como los espacios particulares en el que se ejercía la resistencia al poder. Finalmente la cuadrícula por agregación, ha devenido la formula urbanística para afrontar el rápido crecimiento de la población urbana. Pero "en términos de forma urbana, el rascacielos es también una cuadrícula, vertical por agregación, en la que cada planta repite la estructura de la inferior". Cada piso, se asemeja a una manzana del damero donde el espacio interior abierto o patio es sustituido por el nódulo de servicios (escaleras, ascensores, sistemas de vigilancia); es decir, se ha configurado en cada planta un espacio particular de poder, donde el patio como espacio de resistencia al poder ha sido sustituido por este nódulo central por el que todos están obligados a pasar y que escenifica el poder desde el centro hacia todo el espacio subdividido.

El gran logro de la tecnología inteligente ha sido la vigilancia con la justificación de la seguridad, ante un imaginario externo, ajeno y hostil. En las sociedades avanzadas, las comunidades se han dedicado a aplicar en sus espacios exclusivos dispositivos de control, practicado con cámaras, circuitos cerrados de televisión, vídeo vigilancia, hasta los satélites espía, pero también a inventar mecanismos de controles efectuados sobre 
las grandes poblaciones (Hiernaux-Nicolas, 2014: 43-44). Levantando enormes barreras en forma de edificios de acero y cristal de acceso vigilado (Fig. 3), en esta era postmoderna, la cuadrícula por agregación vertical fue una de las formas eficaces de reinstaurar el orden, el control y la vigilancia sobre una ciudad horizontal donde, cada vez más, iba desvaneciendo su poder de control.

La ciudad vertical que representa la ciudad inteligente, cuyo control desde la cabina de mando permite el acceso selectivo de personas, encarna una "ciudad cerrada" (Sennett, 2019). La regularidad, pureza y simpleza de las formas de sus edificios contrastan con la forma irregular, variada y compleja del resto de edificios de los asentamientos urbanos, allí donde la inestabilidad y la variabilidad de la vida urbana hacen de la ciudad horizontal una ciudad de posibilidades, una "ciudad abierta" (Sennett, 2019).

Está claro, que estas megaestructuras verticales se "ocupan pero no se habitan" (Sennett, 2019: 149). Y el urbanita cualquiera topa con la frontera de la ciudad vertical que le es vetada. Por el contrario, la ciudad horizontal como sistema abierto, de linderos porosos y flexibles permite constantemente invadir espacios bajo la informalidad. Los sistemas abiertos no son destinos sino procesos, en los que se da por supuesto que la vida evoluciona de una u otra manera, y donde se da la convivencia y la interacción, en las que, a su vez, germina constantemente la creatividad social (Sennett, 2019: 252). Los postulados de la ciudad creativa enmarcados en los planteamientos de la "economía creativa" -de origen anglosajón-, lo cierto es que da relevancia al capital humano frente al capital y los recursos naturales pero la clase creativa no está constituida en exclusiva por la clase privilegiada que habita las cumbres como nos la presenta Florida (2009) sino como argumenta Maffesoli (1999: 137):

la ciudad del capitalismo especulativo excluye de facto a las poblaciones no elegidas, pero es la errancia con relación a los valores burgueses establecidos, lo que puede ser una prueba de creatividad e innovación en lo que concierne nuestro tiempo.

La perspectiva que es la manera de visualizar, aprender y apropiarse de los objetos o los edificios, sitúa al observador y usuario de los grandes centros de negocios poblados de rascacielos en la escala de un observador-hormiga. Un edificio es de escala "humana" cuando su perspectiva fuga a la línea de horizonte del observador, que está a la altura de sus ojos. La vista de los rascacielos es la "vista de hormiga" dado que la línea del observador está pegada a la línea del suelo. Cuando la línea de horizonte está por encima del edificio, tenemos la "vista de pájaro". Si bien, la vista de peatón permite percibir de un golpe y reconocer un edificio de escala humana, por el contrario, la vista de hormiga cambia de escala al edificio respecto a la persona, haciéndolo ver de aun mayor tamaño y más lejano. La gran ciudad de los rascacielos no es, por tanto, de escala humana y peatonal. La línea de tierra ha perdido relevancia y la línea del horizonte del observadorpeatón ha desaparecido. En cambio, la línea del cielo o Skyline y la "escala de poder" de estos edificios ha convertido las personas peatones en hormigas. Se ha deshumanizado la gran ciudad, cuya proeza técnico-constructiva y el creciente número de megaestructuras, excluyen el ciudadano de a pie mientras que la vista de pájaro se configura como el foco visual para el nuevo usuario global, eternamente viajero, quien 
ha abandonado las aceras de la calle por el avión.

Jane Jacobs (2011) reconocía la riqueza de la calle y sus aceras como los principales lugares públicos de la ciudad que la aglomeración humana vitaliza siendo el alma de la ciudad. En clara oposición al vacío, al orden evidente y al silencio de la ciudad planificada, "la ciudad es un lugar complejo, lleno de contradicciones y ambigüedades. La complejidad enriquece la experiencia; la claridad la empobrece" (Sennett, 2019: 16). "En una ciudad pequeña, si uno va por la calle Mayor, se tropezará con gente que conoce; amigos, familiares y conocidos". Dentro de los límites de la ciudad pequeña, pueblo grande o barrio, "las conexiones entre sus vecinos crean comunidades funcionales y cohesivas" (Jacobs, 2011: 146). No es así en los nuevos centros de negocio y densas áreas residenciales de torres altas.

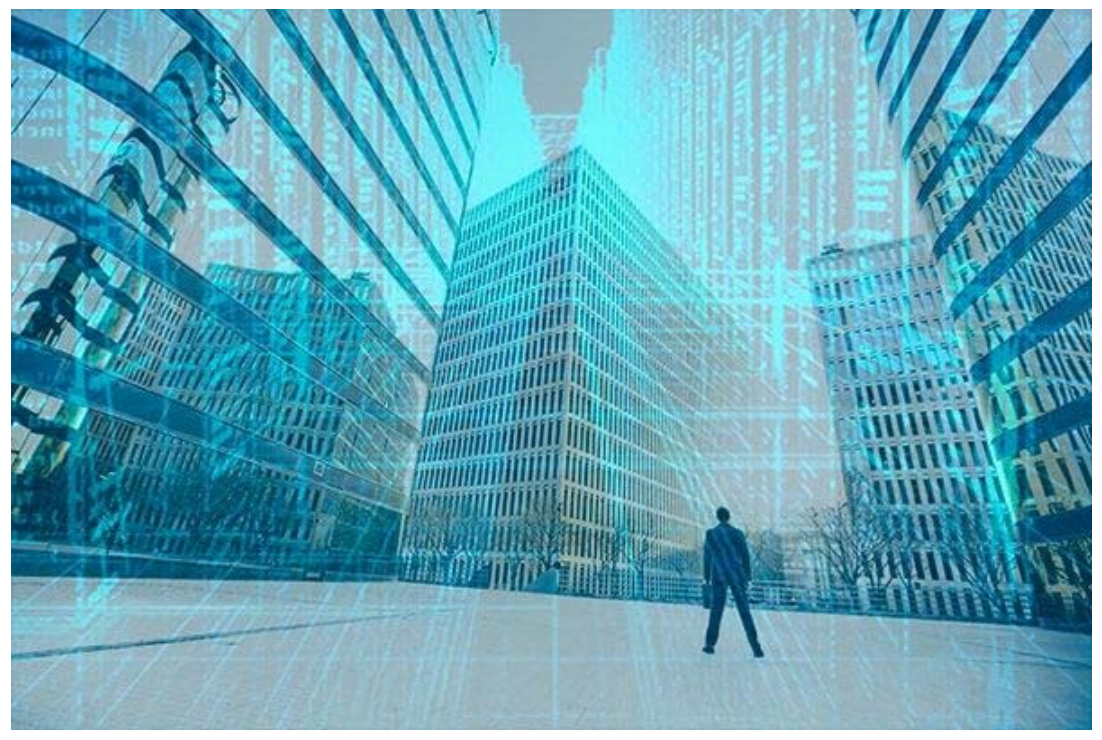

Fig. 3: Gobierno y tecnología, las claves para el desarrollo de ciudades inteligentes basadas en mecanismos de seguimiento y control, Reportedigital, 2019.

Lo cierto es que las ciudades se conocen y se reconocen por sus centros históricos que diferencian una ciudad de otra. Pero la ciudad histórica con sus símbolos hoy se ofrece exclusivamente al consumo turístico y en ella se degrada el ejercicio de la ciudadanía, pues sin espacio público de todos y para todos no hay ciudadanía, sin ciudadanía no hay ciudad. La UNESCO (2019), pone la atención en la creatividad y la innovación de los sectores planos de la ciudad, vinculados al sustrato histórico de su población y de sus edificaciones, sustanciando en ellos los deseos y potencias de cambio, pero lo cierto es que sólo reconoce la ciudad para el turista, olvidando aquellos estratos que naturalizan el nomadismo de la era digital.

Es cierto que en la ciudad contemporánea el modelo de desarrollo horizontal ha dado paso al centro de servicios y gestión de desarrollo vertical. En muchos de los casos, el modelo vertical se ha implantado sobre el modelo horizontal. Los centros puntiagudos, con sus construcciones verticales homogéneas, con lenguaje universal de las formas arquitectónicas abstractas, están convirtiendo al mundo general en una escena única. Así escenarios iguales se encuentran en las nuevas ciudades de China, Siberia o California. 
Aquí y allá se reproducen esas zonas abstractas, sin rostro ni marca a las que Marc Auge (2000: 91) ha venido a denominar los "no-lugares". Lo vivido en este paisaje, para Duvignaud (1977) y De Certeau (2000) sería más bien un pasaje. La "no-ciudad" "dependida de los valores perceptuales del desplazamiento, del cambio y de la inestabilidad como la materia prima de la experiencia urbana” (Delgado, 2007: 61). Si lo construido denota el no-lugar y lo vivido la no-ciudad, por extrapolación su deriva sería el no-ser ya que la existencia se identifica con la localización. "Si el ser sólo puede concebirse como posición lleva a inferir el no-ser como no-posición, lo que es lo mismo: dis-posición, apertura, expectativa ante lo que todo momento está a punto de ocurrir" (Delgado, 2007: 69), lo que describe al "no-urbanita" o n(e)o-urbanita, quien experimenta la nueva gran ciudad, móvil, sin referencias estables.

Si es un hecho que las migraciones mundiales, a pesar de las fronteras internas de las ciudades y de las políticas de emigración, sustancian el nuevo urbanita nómada, los datos confirman el crecimiento de las ciudades por las migraciones. Y esta tendencia no ha hecho más que empezar, según las predicciones de la ONU y en el año 2030 se prevé que más de las dos terceras partes de la población mundial (4.400 millones de personas) serán urbanitas. Las economías creativas de estas grandes urbes basadas a los innovadores y altamente capacitados que ocupan las cumbres más altas y fuertes, no harán más que exacerbar la desigualdad económica y social.

\section{La experiencia tecno-nómada}

Si bien, la definición de urbanita hace referencia a la persona nacida o la que vive en la ciudad, también lo es la persona que vive acomodada a los usos y costumbres de la ciudad. El neo-urbanita es también el sujeto que practica la ciudad, pero dista mucho del urbanita sedentario arraigado a su ciudad y su hogar, sujeto al control institucional.

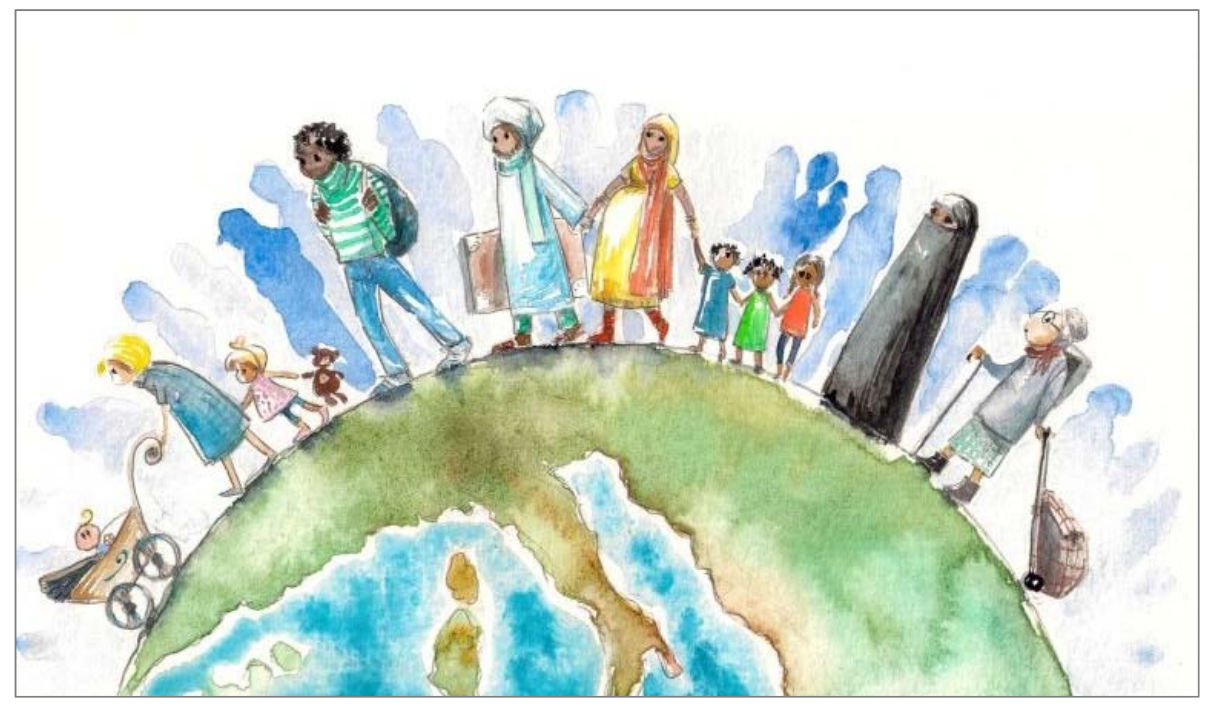

Fig. 4: Migraciones, nomadismo y el elenco de especies urbanas. [Imagen extraída de Cejudo, 2017].

El neo-urbanita se puede clasificar dentro de las categorías del viajero, el turista, el migrante, el nómada global que hoy está aquí y mañana puede estar en otra parte o el nómada urbano que constantemente atraviesa la ciudad de una a otra parte. El neo- 
urbanita es, en la realidad, la conjunción y mezcla del turista, del nativo y del migrante que intercambian costumbres y se contagian modus vivendi (Fig. 4). Porque hay una ciudad de acceso restringido y excluyente, tanto de unos como de otros, el ciudadano se ha convertido en un turista, un extranjero un simple voyeur en su propia ciudad que contempla, pero no puede usar.

Las escalas de redes y circuitos en las que se desenvuelve y tiene acceso el neo-urbanita son, a la vez, de ámbito físico y virtual cotidiano: la red de escala territorial y geográfica de los circuitos y trayectos que practica y la red de escala global, virtual con múltiples contactos en cualquier continente y en tiempo real. Hace pocas décadas serían impensables estas movilidades, las migraciones a nivel global y la vida nómada sin contactos, sin comunicación, sin información, sin la tecnología digital y sin las oportunidades que genera. El migrante del otro lado del mundo (Fig. 5) que nutre las filas de la nueva generación, neo-urbanita, vive en nuestras ciudades conectado, pero sólo, "ya que estos contactos son muy débiles al contrario que el urbanita tradicional que se desenvolvía como un ser eminentemente social, con menos contactos pero más intensos" (Rueda, 2001: 145).

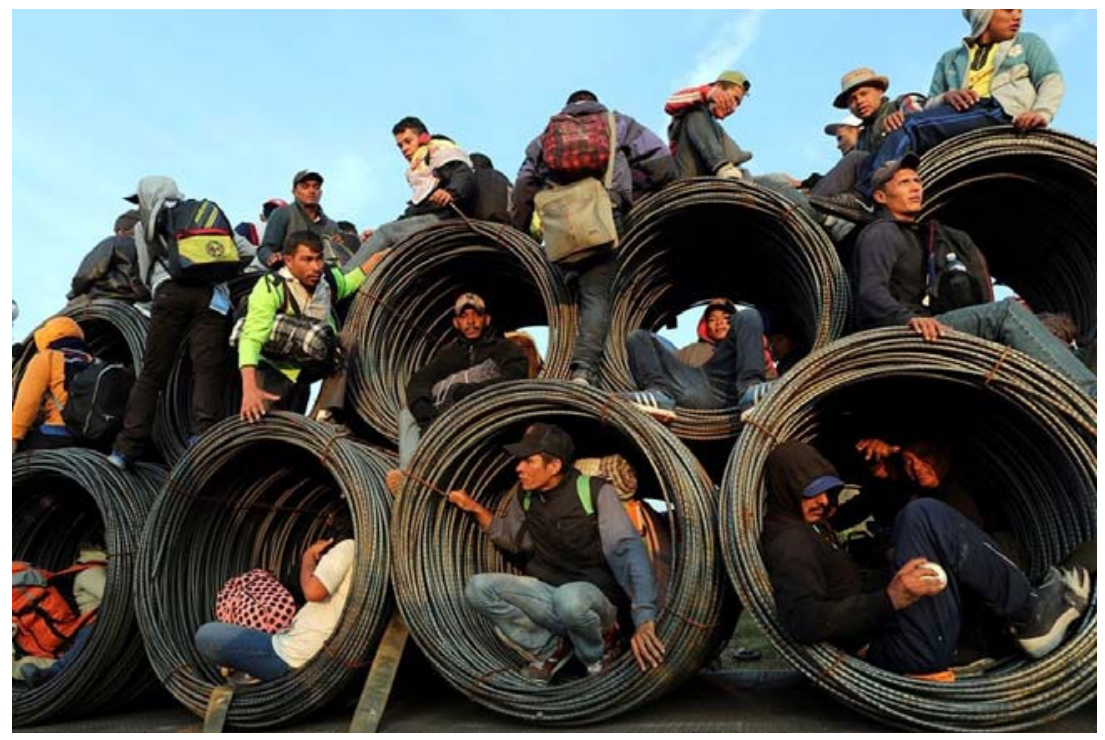

Fig. 5: Migrantes en la gran ciudad. [Fotografía extraída de Pérez, 2019].

En la ciudad excluyente de este contacto físico-corporal, el ser "social" ha devenido un ser "individual". El neo-urbanita, pese a esta soledad, en su entorno virtual cuenta con miles de contactos y amistades a través de las redes sociales que pueda administrar frente a los 10 a 20 contactos físicos del urbanita sedentario tradicional de fines del siglo pasado. Si bien, los pocos contactos físicos daban razón de ser al espacio público, la plaza y la calle como lugares de interacción social-local, las redes virtuales, de algún modo, tienden a sustituir el espacio social, de allí que este personaje solitario sea ahora un ente continuamente conectado a través del chat, con 20 personas a la vez y que tenga cientos de potenciales contactos en espera (Borja, 2014). El individuo global, tanto si es de día como de noche, si es festivo o laboral, el tiempo no importa, puede contactarse gracias a 
una tecnología que le resulte accesible, fácil y sin coste frente a las barreras físicas de la urbe prohibida.

La tecnología $5 \mathrm{G}$ de una capacidad de conexión con todo tipo de dispositivos, además de su alta velocidad de procesamiento de información está contribuyendo a desmantelar "los lugares" y los espacios consolidados para la vida social están restringiendo su acceso como espacios de consumo (Muñoz, 2019).

El neo-urbanita con menos de un metro cuadrado y un teléfono inteligente, tiene su casa a mano, casi todas las actividades del hogar puede realizarlas en cualquier parte con su teléfono móvil; tiene a mano el espacio público con decenas de contactos en tiempo real y también su centro laboral, pues muchas de las nuevas profesiones no son presenciales sino teletrabajos. En su condición de nómada urbano con sólo un mínimo espacio de asiento puede conectarse para intermitentemente llevar a cabo sus actividades cotidianas como, por ejemplo, comer, con las sociales, chatear, las laborales en las plataformas digitales e igualmente con los edificios abstractos de ultra tecnología, pero no acceder, pues "son el lugar de la diferencia” (Borja, 2001: 58).

En las formas de visualizar lo construido entonces, se identifican los actores y lo vivido en sus ámbitos de dominio, subyacentes en "el derecho a la movilidad", no sólo física sino también virtual (Borja, 2001: 60). La descripción más pertinente del neo-urbanita contiene al internauta. A los perfiles del "viajero del aire" (Fig. 6), al nómada global o al extranjero que sólo está de paso por la ciudad, al turista y también al "viajero del suelo"hormiga (Fig. 7), al nómada urbano que ocupa espacios provisionalmente y aquél foráneo que busca oportunidades y trata de establecerse en la ciudad, se suma, mejor dicho, todos ellos son tecno-nómadas incluyendo el inmigrante y al asilado o refugiado, el trabajador precario y ambulante. Como "otro viajero", el peatón nativo urbano cotidianamente se desarraiga de su realidad territorial y es abducido por el creciente y seductor mundo virtual. El nómada digital finalmente engloba todas las categorías que practican la ciudad cotidianamente. La figura que va extinguiéndose es del urbanita estable, sedentario, pues corresponde al ciudadano del siglo pasado y que está envejeciendo también abducido por el mundo virtual y tecnológico. Como afirma Maffesoli (1999: 127,130), se está gestando un nuevo tipo de ciudadano: el de la errancia y el escapismo.

La figura del neo-urbanita se caracteriza por la alta movilidad y la conversión digital. "Las nuevas tecnologías se han convertido en una segunda naturaleza" (Hall, 2001: 43). El alejamiento de la familia y el hogar hace que encuentre el calor de hogar en las redes sociales virtuales. Entonces, para el neo-urbanita "su hogar es ahora la ciudad y su ciudad es el mundo". Como decía Toyo Ito (2000: 46), la chica nómada de Tokio "sólo puede reconocer la casa uniendo varias de sus funciones que están esparcidas en medio de la ciudad como si fueran pedazos de un cristal roto", en clara alusión a la familia fragmentada y la vida tipo collage. 
"Para ella, el salón es el café bar y el teatro, el comedor es el restaurante, el armario es la boutique, y el jardín es el club deportivo. La muchacha nómada deambula por estos espacios muy de moda y pasa la vida cotidiana como en un ensueño" (Ito, 2000: 62).

Si físicamente la ciudad es su hogar, de igual manera, virtualmente el mundo es ahora su ciudad y cada vez más tiende a ser una realidad "la fisión de los hogares, el descenso del tamaño medio de las familias y el rápido incremento de individuos que viven solos" (Hall, 2001: 30).

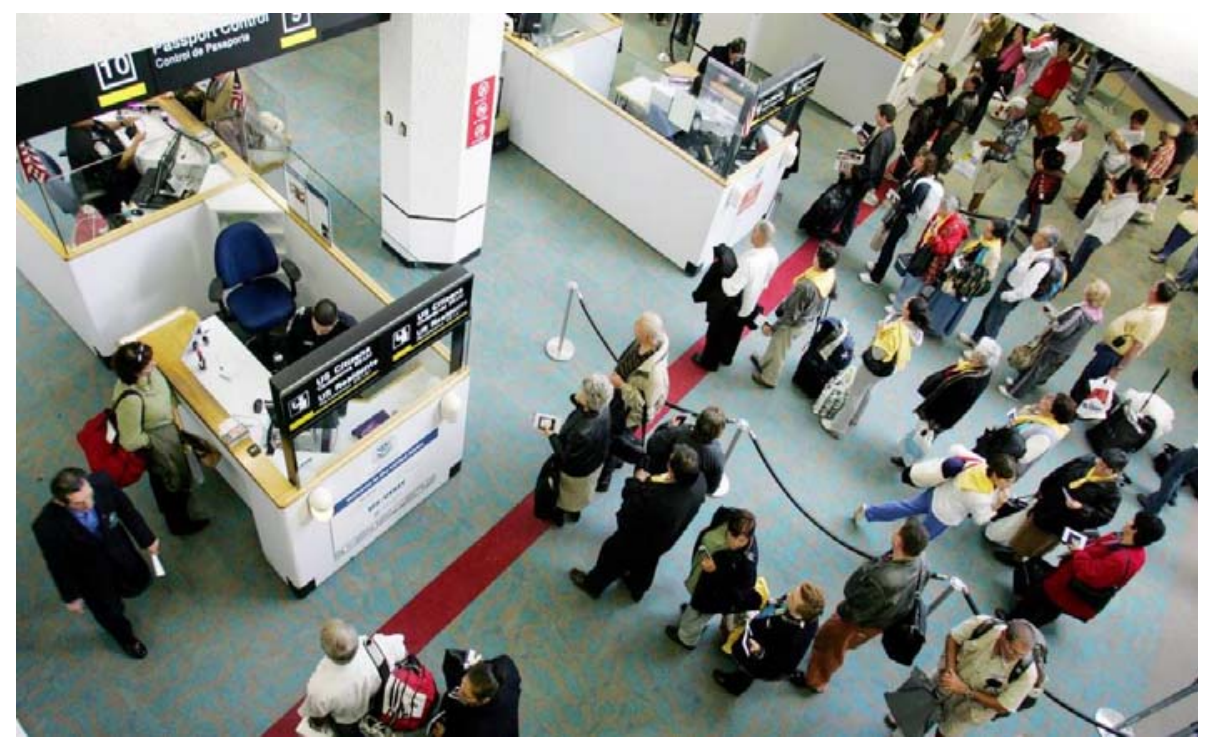

Fig. 6: Viajeros del aire [Fotografía extraída de Shoer Roth, 2019].

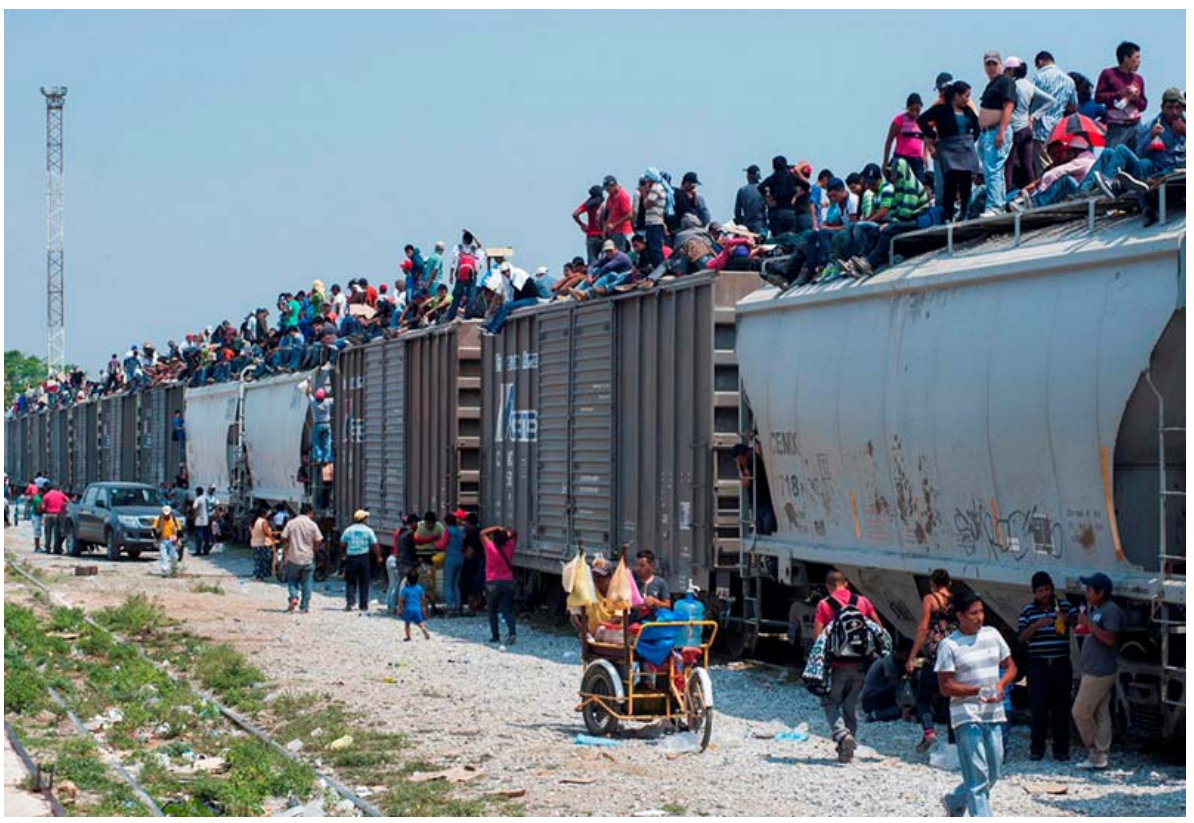

Fig. 7: Viajeros del suelo en búsqueda de oportunidades [Fotografía extraída de Fuentes, 2018].

La "generación Z" es una generación líquida que pese a su poca inserción en el mercado laboral son muy creativos, con una alta adaptabilidad a nuevos entornos (Vilanova y 
Ortega, 2017). Saben que tendrán que adaptarse muchas veces a nuevas realidades laborales y tener mucha movilidad geográfica en un mundo global. El nomadismo digital, que utiliza Internet para desempeñar ocupaciones diversas, trabajando de forma remota, lo que le permite a uno poder vivir viajando, sin duda, está configurando el nuevo estilo de vida (Fig. 8). Este nuevo estilo de lo vivido se disocia de lo construido.



Fig. 8: Generación Z, nacidos con dispositivos electrónicos y consumidores de redes sociales, Muypymes, 2017.

\subsection{El turista y el transeúnte}

Si la característica natural del neo-urbanita es su alta movilidad, "ubicación" y "localización”, en su jerga, resultan conceptos abstractos. Este nuevo protagonista de la gran ciudad, conceptualmente el individuo que configuran las distintas modalidades del movimiento, es entendido ya no como punto localizado en el espacio sino a través de redes y tramas de los distintos desplazamientos que lo identifican (Delgado, 2007: 63).

"Los ciudadanos viven la trama urbana con naturalidad expresando su opinión con los pies, no con la cabeza. Utilizan más o menos los espacios urbanos y cada uno tiene su trama subjetiva. La forma de la ciudad se subjetiva según sus trayectos cotidianos" (Borja, 2001: 61).

Según Kevin Lynch (2013), la ciudad tradicional proporcionaba sentido de orientación y un conjunto mental articulado que podría retenerse en la memoria pues, cada sujeto, de manera individual, podría trazar sus mapas. "Un espacio en el que la gente es incapaz de construir mentalmente mapas (...) es pues, la forma que el neo-urbanita, se aproxima a la ciudad genérica y abstracta” (Borja, 2001: 62).

Si bien, el paisaje puntiagudo del mundo de Florida parece ser la ciudad del futuro, en este mapa de cubres y valles se confirma la creciente segregación y fragmentación social en el espacio y se acentúan las diferencias entre las figuras del urbanita contemporáneo móvil. Entre ellas es destacable la del "turista" o "paseante" (Fig. 9) y del "transeúnte" migrante de uno a otro lado de las fronteras de un universo hecho de fragmentos y discontinuidades (Delgado, 2007: 69). 
Los dominios del primero se identifican como el dentro y el afuera. El adentro se asocia con el interior de los edificios y recintos exclusivos y vigilados y el afuera, dominio por excelencia del transeúnte, pues sólo representa los lugares de paso. La experiencia de habitar la urbe contemporánea, sin embargo, no diferencia, más bien articula lo que está dentro y fuera de un recinto y permite ir más allá de la desgastada dicotomía entre lo público y lo privado, que usualmente ha sido reproducida casi mecánicamente como espacio público y espacio privado. Esa dicotomía resulta superada constantemente en la vida urbana contemporánea por la emergencia de lo público dentro de lo privado y también cada vez que lo privado se presenta en público gracias a las nuevas tecnologías (Lindón, 2014: 68). Las redes, permiten que las calles de la ciudad penetren en el espacio privado a través de los medios de comunicación y de los innumerables espacios de consumo: comida, entretenimiento, cultura, educación, información, servicios online que vienen a suplantar la vida en los espacios públicos abiertos.

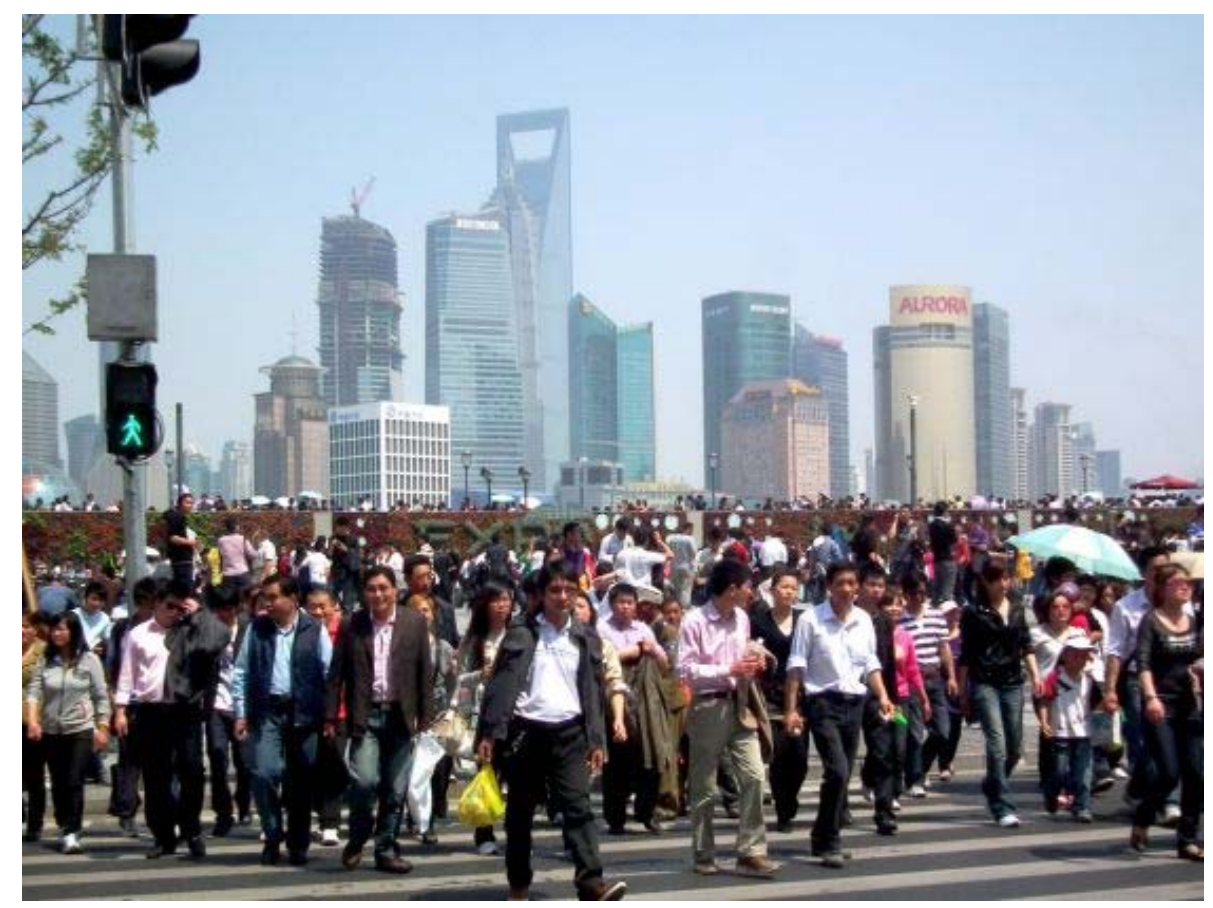

Fig. 9: Turistas junto al río Huangpu, con fondo el distrito financiero de Shanghái, Reinoso, 2013.

La ciudad inteligente se perfila así con espacios restringidos y privados mientras que las nuevas tecnologías de gestión del espacio público ofrecen una diversidad de información y servicios accesibles. Hajer y Dassen (2014) la describen como una distopía. "Las tecnologías urbanas producirán ciudades más seguras, más limpias y, sobre todo, más eficientes [...] donde se implementan, que no es por igual al conjunto de los aglomerados urbanos". Los nuevos productos y servicios tecnológicos que las grandes multinacionales ofrecen al mercado, en combinación con las políticas localizadas proporcionan seguridad, confort y eficiencia a las comunidades que tienden a una, cada vez, mayor monitorización y "robotización”. Cada vez, más sensores instalados perciben las conductas que se convierten en macrodatos y poder para los que utilizan esta retroalimentación para gestionar las dinámicas urbanas y reajustar los servicios (Sennett, 2019: 206). 
La mecanización de la ciudad, la automatización y finalmente la "cibernética" y la monitorización permanente desde el centro de control de la ciudad inteligente, ya representa la aspiración de los planificadores de crear un modelo sobre la base de la gestión de una ciudad a la manera que un piloto conduce un avión. Esta manera de gestión hace que las ciudades inteligentes (por hoy pequeñas como Songdo en Seúl y Masdar en Abu Dabi), se constituyan en islas o guetos urbanos, donde la única posibilidad de acceso para los urbanitas de a pie es bajo la condición de turista o curioso embeleñado por el espectáculo que se presenta ante su visión; o la de un transeúnte desde la lejanía, a la velocidad del automóvil u otro transporte. La versión que ya es dada con más frecuencia son las "islas inteligentes" distinguidas dentro de los "archipielagos" o aglomeraciones urbanas de las megaciudades (Brand, 2009).

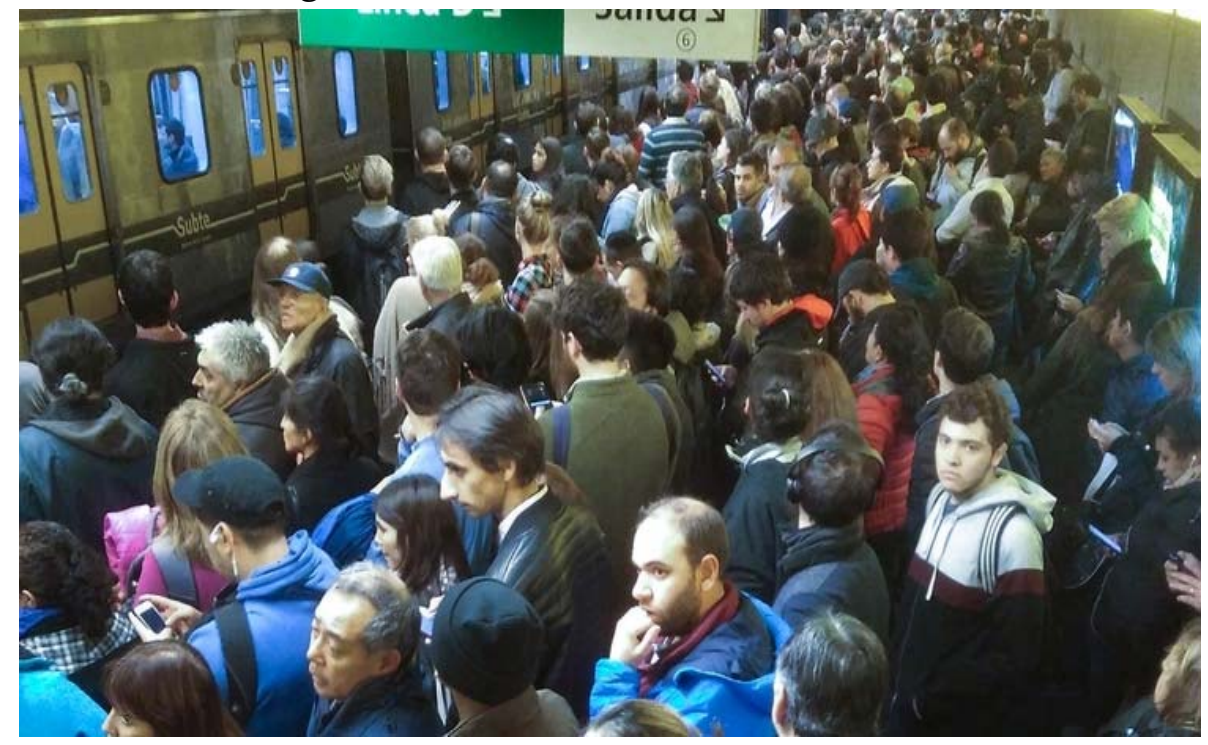

Fig. 10: Largas horas de viajes en condiciones que afectan la calidad de vida urbana, Infobae, 2019.

La ciudad de los rascacielos la ocupa una clase exclusiva y el resto la contemplan como visitantes. La figura del "paseante" se hace patente básicamente por el "turista" y no solamente el extranjero, sino el nacional y también el local que forman parte de los que realizan viajes voluntarios, y los que realizan viajes de trabajo: conferenciantes y asistentes a eventos y congresos internacionales, agentes de negocios, pilotos de avión, y otros. La figura del transeúnte, su grueso lo constituye la población en constante traslado (Fig. 10). Encontramos viajando desde los que se movilizan por situaciones laborales, inmigrantes, informales y trabajadores temporales, ilegales, los que escapan a los sistemas de control y vigilancia y otros vagabundos modernos en busca de oportunidades. Oportunistas, aventureros, ladrones y maleantes forman parte de la diversidad que transita por la planicie y se traslada en los medios de transporte masivos (Maffesoli,1999). Toda esta masa nómada, no conoce más que la vida móvil y los lugares de paso (Delgado, 2007). Los patrones de movilidad urbana en las zonas metropolitanas arrojan datos como, por ejemplo, 34.5 millones de viajes, en un día entresemana en la Ciudad de México, de los cuales $22 \%$ son desplazamientos por motivos laborales (Encuesta Origen-Destino 2017), (Baruch, 2019). 
El nomadismo transurbano vive en la velocidad y consume el tiempo en el traslado recorriendo los dispersos fragmentos de la gran ciudad, yendo y volviendo para resolver su subsistencia. El otro recurso es la red y el dispositivo móvil, el tecno-nomadismo practicado en las redes. Telecomunicación y teleproducción son características de la vida nómada contemporánea que pierde, cada vez más, contacto con las estructuras físicas y modifica progresivamente la identidad del urbanita. Espacio público y espacio privado, comunidad e individualidad, son oposiciones debilitadas que tienden a desaparecer. La desintegración de la calle, la fragmentación y la dispersión de la ciudad lleva, según Borja (2014: 22) a una "atomización de la sociedad".

Así el urbanita de hoy es un individuo que practica la ciudad como nómada urbano y presenta al menos dos figuras arquetípicas en función a su experiencia con la ciudad y con respecto el tiempo y la velocidad: el "transeúnte" y el "turista". El transeúnte es el que, en la rutina cotidiana, en sus desplazamientos en la gran ciudad se relaciona con los modos de vida acelerados tratando de optimizar el uso del tiempo. Los desplazamientos en transporte público o en automóvil particular comparten la misma experiencia reducida del espacio recorrido en un trayecto que une dos puntos: el de partida y el de llegada y entre ellos nada (Lindón, 2014: 70-71). El paseante sin embargo "hace algo más que ir de un sitio a otro. Haciéndolo poetiza la trama ciudadana, la somete a prácticas imaginarias que hacen del plano de la ciudad el marco de una experiencia individual, "elocuencia geométrica y una verbosidad hecha con los elementos que se va encontrando a lo largo de la marcha" (Delgado, 2007: 71). El paseante o "turista" teje una trama urbana entre el centro urbano y ciertos lugares aledaños, pero nunca hasta los enclaves periféricos o planicies marginales. La ciudad turística, centro histórico, temático de atracción, consumo y ocio, cada vez más, reduce la posibilidad de ser habitada y sólo puede ser paseada y contemplada.

Por el tiempo corto y la aceleración de los viajes, el turista moderno no profundiza ni se identifica con los nuevos lugares y las nuevas gentes que llega a conocer (HiernauxNicolas, 2014: 47). El turista encarna a ese personaje global movido para conocer los sitios que la oferta global bombardea continuamente su ordenador y su teléfono móvil. El transeúnte se apropia sin matices de lugares de la gran ciudad que canaliza los flujos del nomadismo urbano de distintas velocidades.

\subsection{El sinhogarismo y la familia ausente}

La casa y el hogar en la zona de atracción, que es el reino del turista, en este último lustro se está transformando en "piso turístico" hasta tal punto que se hace necesario tomar medidas, poner freno a la invasión de pisos turísticos y evitar la expulsión de las familias y los hogares.

Las zonas de confluencia del urbanita también están experimentando transformaciones en su dinámica social. Los pisos de alquiler turístico de la zona de atracción se han expandido en estas zonas intermedias, nutridas de espacios para la socialización, comercio y servicios donde las enormes demandas estimuladas por las plataformas 
digitales ocasionan la presencia, cada vez mayor, de "extraños". Y aquí también la vida privada de los hogares, cada vez más, se mezcla con los extraños.

Si el desplazamiento y la disociación de la familia y el hogar tradicional es un hecho imparable con la presencia constante de extraños, una especie de compensación a la unidad de la familia es que se convierten también en viajeros recurrentes. Insertos en el consumismo global, reemplazan el salón por el restaurante, la cocina por delivery y ocupan muy diversos locales a lo largo del día donde desempeñan actividades y tareas (Ito, 2000) engrosando las filas del nomadismo contemporáneo. Indirectamente se establece un círculo en el cual la familia tradicional y sedentaria ahora nómada se mueve, alentados sus miembros por las ofertas de consumos, principalmente en la red, por la tecnología a mano y la tenencia de automóvil.

Con conductas y comportamientos cuya auténtica fuerza reside en aprender a convivir con el desplazamiento, en el nuevo modelo de urbanita, pues no se reconoce pertenencia ni allí, ni aquí, ni entonces, ni ahora. Se ha convertido en el cosmopolita esencialmente desarraigado y apátrida o que su "patria es móvil" (Sennett, 2019: 255-256). Además, el volumen del flujo de inmigrantes por causas que activan las movilidades poblacionales a escala territorial global, como la "crisis climática", las catástrofes naturales, las guerras $\mathrm{y}$ otras formas de violencia que expulsan las poblaciones del tercer mundo hacia el primer mundo así como el segundo éxodo rural hacia las grandes aglomeraciones urbanas de los mismos países, que a consecuencia de las inmigraciones están creciendo cada vez más, están causando cambios demográficos y la rápida urbanización de los centros de servicios, fundamentalmente, a gran escala en la población mundial. En los próximos lustros estarán desestabilizando las instituciones y los gobiernos, quienes, ante el inusitado incremento de población flotante, no tienen capacidad de respuesta inmediata a cuestiones emergentes, como la vivienda, la sanidad, la educación y otros servicios.

Las migraciones seguirán formando pues el grueso de las sociedades urbanas, y la llegada de inmigrantes MENA (Menores Extranjeros No Acompañados -), que al cumplir los 18 años salen de la tutela de la administración, engrosarán las filas de jóvenes con difícil acceso a la vivienda, por su alto precio, factor clave para determinados colectivos y particularmente los jóvenes, que apunta hacia el aumento del "sinhogarismo" (EFE 2019). Pues, no son sólo los que viven en la calle, que son muchos, sino los que viven provisionalmente en casas ajenas, en colmenas, en alojamientos para temporeros y otros establecimientos precarios, insalubres y faltos de higiene. El titular informa que "los sin techo aumentan un $24 \%$ en Madrid...”. En dos años, de 2583 personas sin hogar, se han reportado 650 en estricta situación de calle, quienes buscaban un hueco en locales comerciales, cajeros y bocas de metro para pasar la noche (Pelayo, 2019).

La calle es lo que conoce el migrante y también el vagabundo sin techo y todos los urbanitas, "una vez que han abandonado la seguridad de la familia y su lugar por el deseo de nuevas experiencias que los ha impulsado a marcharse, "o bien puede ser que la nueva experiencia se les imponga" (Sennett, 2019: 262). 
En la sociedad individualista el hogar no es el sitio de la convivencia y a la familia la rehúyen ahora no sólo los hijos sino también los padres, ya no es "el lugar". Pero tampoco encuentran su lugar en esa ciudad que cotidianamente los excluye en "un rehacerse incesante (...) por seres transeúntes que tratan de acomodarse como pueden a la ausencia de lugar" (Delgado, 2007: 63). Los lugares negados se sustituyen por un tipo de lugares de presencias, de los umbrales o de las mediaciones donde el sentido de lo comunitario se cristaliza en ausencia del hogar y de la sociedad institucionalizada. Las comunidades virtuales se visibilizan entonces, asumiendo roles de la ciudad negada. Comunidades nacionales, étnicas, de género, religiosas y otras desarrollan constantemente mecanismos instituyentes de identidad y superación a través de la «creatividad» rompiendo frentes continuamente y muy especialmente una población juvenil pasa a representar la vanguardia del urbanita nómada.

Si la condición nómada señala la errancia, el vagabundeo y el escapismo entonces debe oponerse a aquello que Maffesoli (1999) explica como la relación de la vida y de los valores modernos con el sedentarismo en la ciudad, es decir, con aquello que se presenta bajo la idea de unas fronteras definidas dentro de las cuales nada escapa a la vigilancia del poder. Ruales (1997) identifica en su obra literaria un doble viaje efectuado como escape del poder que controla la ciudad, y también como escape de la autoridad de la madre "quien impone el sistema disciplinario y de vigilancia dentro del hogar" (Rodríguez, 2011: 8). El nómada se reconoce por "su móvil que no es otro que un deseo de evasión, la libertad de espíritu". "No se reconoce en los encierros institucionales de cualquier tipo, sino que halla su origen en un enfrentamiento común del destino vivido de manera proxémica". Representa lo "instituyente", en plena gestación, frente a la ciudad "instituida" (Maffesoli, 1999: 139-140). A diferencia de la migración, no es únicamente la necesidad económica o la simple funcionalidad, su móvil. Quizá lo que pasa desapercibido es que, en cada emigrante, en distinta proporción se encuentra el aventurero y el ensoñador. Es una especie de "pulsión migratoria" que incita a cambiar de lugar, de hábito, de compañeros, y ello para realizar la diversidad de facetas de su personalidad. La confrontación con el exterior, con el extraño y el extranjero es lo que permite al individuo vivir esta "pluralidad estructural que está dormitando en cada uno" (Maffesoli, 1999: 132). Sin embargo, tras ese móvil, subyacen nuevos aspectos que hacen que la nueva juventud tenga naturalizado el nomadismo como parte insoluble a su ser.

Al disociarse el espacio físico, lo construido, del espacio social, lo vivido, asistimos a un cambio radical de la percepción del entorno que nos rodea. Si la ciudad practicada se sustanciaba en lo social en acción, "hecha de ocasiones, secuencias, situaciones, encuentros y de un intercambio generalizado e intenso de presencias" (Delgado, 2007: 16), en él se reconocían tres niveles de proximidad: lo privado o lazos primarios de familia y amigos íntimos, lo que concierne a la "intimidad"; lo comunitario, que comprendía a las personas en una misma red social (religiosa, vecinal, profesional, deportiva, etc.), con "afinidad"; y, lo público, que reúne las relaciones entre desconocidos o conocidos de vista, los "extraños". Estos niveles de proximidad determinaban a su vez una configuración espacial que correspondía a cada uno de los niveles de la ciudad. Lo 
privado ubicado más bien en áreas residenciales en las periferias mayoritariamente, lo público generalmente en el centro de atracción, histórico, terciario, financiero y lo comunitario que parece no tener espacio en esta configuración. Resulta, sin embargo, lo más importante. Lo más parecido a los espacios comunitarios y de encuentro son los "espacios de mediación" por donde los urbanitas ejercen el "derecho a la movilidad" cotidiana constante y transitan en libertad, pues estos no sólo relacionan enclaves periféricos con un centro de atracción, sino enclaves con enclaves. Son lugares de paso y de confluencia como centros comerciales, de consumo y ocio, intercambiadores de transportes, líneas de transporte, autopistas, gasolineras y estaciones de servicios, estaciones, aeropuertos, clubs y áreas de deporte, etc.

Además, el sinhogarismo y la familia ausente están dando paso a nuevos referentes, las comunidades virtuales que están generado nuevos espacios para la producción y el intercambio social como los co-working, los co-living y los crowdfunding. En este sistema inestable de relaciones y espacios se construyen las subjetividades nomádicas cuya vanguardia instituyente es la nueva llamada generación $\mathrm{Z}$, la que experimenta en las filas del nomadismo y la errancia, con mayor facilidad el acceso a las oportunidades donde las haya. Ya no importa quiénes son sus padres o dónde han nacido, cuentan con un talento, son nativos digitales y aprovechan esta ventaja para buscar nuevas salidas laborales en un mercado cambiante. Son jóvenes creativos, con una alta adaptabilidad a nuevos entornos. Saben que tendrán que adaptarse muchas veces a nuevas realidades laborales y tener mucha movilidad geográfica en un mundo global. Según Vilanova y Ortega (2017), estos jóvenes "ya están inventando sus propios empleos" instaurando el binomio juventud y tecnología, de hecho, pasan entre 6 y 10 horas conectados a sus móviles.

No cabe duda que esta nueva generación, hijos en su mayoría de padres inmigrantes asentados en estas grandes aglomeraciones urbanas, son los ciudadanos globales, cuyos contactos y amistades son más plenas y fluidas con sus pares del mundo que con sus vecinos del piso de a lado. Al contrario que la generación milenial o generación $\mathrm{X}$ de los nacidos entre 1968 a 1993, que antecede a la generación Z, que en su juventud experimentaron la gran innovación tecnológica de la década de los $80^{-}$y que son obsesionados por el triunfo a toda costa, sus valores encajan mejor en la vida móvil e inestable.

\section{Conclusiones}

De lo argumentado se vislumbra el tecno-nomadismo como tendencia de futuro. La experiencia tecno-nómada de la ciudad progresivamente se instala. Se está gestando un nuevo tipo de nómada global, como el consumidor que se mueve entre la "nube" y la gran ciudad extraña, extrapolarizada, que no hará más que polarizar su extrañamiento y su indiferencia. Lo cierto es que la gran ciudad que evolucionó a partir de la ciudad histórica anclada en el suelo firme, su población sedentaria y sus instituciones, se despega hacia las nubes y el sedentarismo "anacrónico" va desapareciendo activándose de forma acelerada un nomadismo tecno. 
En las megaregiones y megaciudades articuladas a través de autopistas y trenes de alta velocidad, las actividades y las localizaciones que se dispersan convierten los ciudadanos en perpetuos migrantes. Todo estalla en fragmentos en la ciudad global y debido a esta constelación y las redes como actor principal, el urbanita nace, vive y morirá en la dispersión, la vertiginosidad del cambio, siempre en lo nuevo que lo abduce, en soledad y desarraigo.

Pero tal condición se naturaliza y no se vive como drama, si bien es verdad que no es la misma condición la del emigrante económico forzado que la del ciudadano del mundo con recursos que elige la vida nómada. La creatividad y la innovación, no obstante, subyacen en ambas trayectorias como motor de cambio social. Somos, de hecho, la población más móvil de toda la historia de la humanidad porque se dan los medios, la civilización que se superpone a las culturas y en esta sociedad actual, tan extremadamente móvil, tecnológicamente avanzada e interconectada, las oportunidades de construcción de las individualidades dependen mucho de la capacidad de moverse y de la posibilidad de trasladarse.

Dentro de los límites de esta investigación, nuestro entendimiento antropológico del urbanita nómada y sus redes, la sociedad móvil y la arquitectura de la gran ciudad del siglo XXI se argumentan como dos estructuras que se están separando. La polarización "ciudad vertical" inteligente de la "clase creativa" y "ciudad horizontal" expandida como consecuencia de las aglomeraciones poblacionales en continuo incremento por la migraciones internas y globales, no son espacialidades de pertinencia de unos y otros y definitivamente en la gran ciudad global de hoy no hay correspondencia entre lo construido y lo vivido.

En la ciudad puntiaguda que se ancla en la nube virtual y a la red de tráfico aéreo se visualiza la vida ultramoderna desarraigada de la horizontalidad terrestre. La ciudad tecno-vanguardista de los aires, parece erigirse para ser vista y contemplada por aquel transeúnte-hormiga y el turista paseante o por aquel viajero del aire que puede asombrarse ante su imponente presencia. En los picos labora "la clase creativa" de Florida y los inmigrantes van a hacer turnos de otros trabajos, tanto de día como de noche. Entre los centros de negocios y la ciudad extensa se genera la tensión del deseo de cambio de este sector convertido en la energía humana que mueve la gran ciudad. La condición nómada se contempla aquí como el deseo de cambio y la creatividad en todas sus facetas. Las subjetividades nomádicas desprendidas de las estructuras estables, no tienen zona de confort; se arrojan al riesgo, la experimentación, la invención y la autoinvención en la gran ciudad entre extraños. La construcción de las nuevas subjetividades a partir de recursos creativos resulta motor de todo cambio que afecta lo social. En este cambio es rasgo principal la sociabilidad espacial que progresivamente se desplaza hacia las redes virtuales. La disociación entre lo vivido y lo construido.

\section{Referencias}

AUGÉ, M. Los «no lugares» espacios del anonimato: una antropología de la sobremodernidad. $5^{\underline{a}}$ 
reimpresión. Barcelona: Gedisa, 2000. 125 páginas. ISBN: 84-7432 -459-9.

BARUCH, J. Origen y Destino de los trabajadores en la Ciudad de México[En línea]. Medium: 1 junio 2019 [Consulta: 15 de junio de 2019]. Disponible en: https://medium.com/@datavizero/origen-y-destino-de-lostrabajadores-en-la-ciudad-de-m\%C3\%A9xico-4c5e9dfd6e3d

BORJA, J. “La ciudad del siglo XXI. El desafio del espacio público”. En: Jordi Borja, et al. (aut.). Ciudad para la sociedad del siglo XXI. Valencia: ICARO, 2001, Vol. 1, p. 55-79.

BORJA, J. “Prólogo”. En: Diego Sánchez y Luis Ángel Domínguez (coords.). Identidad y espacio público: ampliando ámbitos y prácticas. Barcelona: Gedisa, 2014, p. 9-23.

BRAND, P. “La globalización neoliberal y la planeación urbana: perspectivas para América Latina”. En: Peter Brand (edit.). La ciudad latinoamericana en el siglo XXI:globalización, neoliberalismo, planeación. Medellín: Universidad Nacional de Colombia, 2009, p. 7-33.

CEJUDO, C. "Migraciones y talento” [En línea]. Cadena SER Radio online. Madrid: 22 enero 2017. GETTY IMAGES [Imagen digital].

https://cadenaser.com/programa/2017/01/20/a_vivir_que_son_dos_dias/1484921468_170237.html [Consulta: 12 enero 2020].

CERTEAU, M. de. La invención de lo cotidiano. 1 Artes de hacer. Reimpresión 1ae edición en español. México: Cultura Libre, 2000. 229 páginas. ISBN: 968-859-253-6.

DELGADO, M. Sociedades movedizas: pasos hacia una antropología de las calles. $1^{\text {a }}$ edición. Barcelona: Editorial Anagrama, 2007. 275 páginas. Colección Argumentos. ISBN: 978-84-339-6251-5.

DUVIGNAUD, J. Lieux et non lieux. Paris: Éditions Galilée, 1977. 153 páginas. Collection La philosophie en effet. ISBN: 2718600705.

EFE. “¿Cuántos menas hay en España?” [En línea]. El Confidencial. 06 agosto 2019. https://www.elconfidencial.com/espana/2019-08-06/cuantos-menas-espana_2164951/ [Consulta: 22 de enero de 2020].

EL COMERCIO. Estas son las ciudades más grandes del mundo[En línea]. 04 de diciembre de 2018 [Consulta: 20 de febrero de 2020]. Disponible en Web: https://www.elcomercio.com/construir/brasilciudades-grandes-mundo-construir.html

FLORIDA, R. Las ciudades creativas: por qué donde vives puedes ser la decisión más importante de tu vida. 1ª edición. Barcelona: Paidós, 2009. 368 páginas. ISBN: 978-84-493-2204-4.

FRIEDMAN, T. La tierra es plana: breve historia del mundo globalizado del siglo XXI. 1르 edición. Madrid: Martínez Roca, 2007. 495 páginas. ISBN: 978-84-270-3222-4.

FUENTES, M. "Migraciones irregulares: una mirada crítica” [En línea]. Cindy López y Marcelo Colussi (aut.). Prensa Comunitaria. Abril 2018. UDGTV.COM [Fot.]. https://www.prensacomunitaria.org/migracionesirregulares-una-mirada-critica/ [Consulta: 21 diciembre 2019].

GUATTARI, F. Las tres ecologías. José Vásquez y Umbelina Larraceleta (trad.). 2a edición. Valencia: PreTextos, 1996. 79 páginas. ISBN: 84-87101-29-1.

HAJER, M. y DASSEN, T. Smart about cities: visualising the challenge for 21st century urbanism: "we need a globally networked urbanism". Rotterdam: Nai010 Publishers, 2014. 183 páginas. ISBN: 978-94-620-8148-2.

HALL, P. "La sociedad emergente: mundo urbano en 2025”. En: Jordi Borja, et al. (aut.). Ciudad para la sociedad del siglo XXI. Valencia: ICARO, 2001, p. 29-53.

HIERNAUX-NICOLAS, D. “Identidades cosmopolitas y territorialidades en las sociedades posmodernas”. En: Diego Sánchez y Luis Ángel Domínguez (coords.). Identidad y espacio público: ampliando ámbitos y prácticas. Barcelona: Gedisa, 2014, p. 41-53.

INFOBAE. Migraciones, problemáticas urbanas y ciudades inteligentes [En línea]. Fernando Calzada (fot.). 19 octubre 2019 [Consulta: 24 de marzo de 2020]. Disponible en Web: 
https://www.infobae.com/def/desarrollo/2019/10/19/migraciones-problematicas-urbanas-y-ciudadesinteligentes/

ITO, T. 2000. Escritos. José M. Torres (ed.); Maite Shigako (trad.). Murcia: Colegio Oficial de Aparejadores y Arquitectos Técnicos, 2000. 249 páginas. Colección de Arquitectura, Vol. 41. ISBN: 84-89882-12-6.

JACOBS, J. Muerte y vida de las grandes ciudades. Ángel Abad y Ana Useros (trad.). 2a edición. Navarra: Capitán Swing Libros, 2011. 487 páginas. ISBN: 978-84-938985-0-2.

LINDÓN, A. El habitar la ciudad, las redes topológicas del urbanita y la figura del transeúnte. En: Diego Sanchez y Luis Ángel Domínguez (coords.). Identidad y espacio público. Barcelona: Gedisa, 2014, p. 55-77.

LYNCH, K. La imagen de la ciudad. 1ª edición. Barcelona: Gustavo Gili, 2013. 224 páginas. ISBN: 978-84-2521748-7.

MAFFESOLI, M. "Nomadismo fundador". Nómadas. 1999, vol. 18, núm. 10, p. 126-142.

MUÑOZ, R. “La nueva guerra fría del 5G” [En línea]. El País. 9 junio 2019. https://elpais.com/economia/2019/06/06/actualidad/1559835295_419007.html [Consulta: 16 de julio de 2019].

MUYPYMES. Generación Z: talento digital y nuevos retos empresariales[En línea]. 02 febrero 2018. [Consulta: 18 de agosto de 2019]. Disponible en Web: https://www.muypymes.com/2018/02/02/generacion-z-talento-digital-nuevos-retos-empresariales

PARK, R. "The city: suggestions for the investigation of human behavior in the urban environment”. En: Richard Sennett (ed.). Classic essays on the culture of cities. New York: Appleton-Century-Crofts, 1969, p. 91130.

PELAYO, F. "El número de personas 'sin techo' crece en Madrid más de un 25\% y se saturan los albergues durante el invierno" [En línea]. 20 Minutos. 11 abril 2019.

https://www.20minutos.es/noticia/3611553/0/numero-personas-sin-techo-crece-madrid-saturanalbergues-invierno/ [Consulta: 12 mayo 2019].

PÉREZ, M. F. Análisis Migraciones: ¿qué pasa cuando la humanidad se mueve?[En línea]. CLARÍN: 13 de enero de 2019 [Consulta: 05 de octubre de 2019]. Disponible en Web: https://www.clarin.com/viva/migraciones-pasa-humanidad-mueve_0_ZSEvt85iE.html.

PORTER, M. Q\& A with Michael Porter[En línea]. 21 August 2006 [Consulta: 12 de octubre de 2019].

Disponible en Bloomberg Businessweek Web: https://www.bloomberg.com/news/articles/2006-08-

20/online-extra-q-and-a-with-michael-porter

REPORTEDIGITAL. Gobierno y tecnología: Las claves de la innovación y desarrollo de las Ciudades Inteligentes [En línea]. 10 octubre 2019 [Consulta: 22 de diciembre de 2019]. Disponible en Web: https://reportedigital.com/iot/gobierno-y-tecnologia-las-claves-para-el-desarrollo-de-ciudadesinteligentes/.

REINOSO, J. “China lanza una masiva campaña de migración del campo a la ciudad” [En línea]. Zhang Heping (fot.). El País. 30 marzo 2013.

https://elpais.com/internacional/2013/03/30/actualidad/1364658274_571903.html [Consulta: 21 octubre 2019].

RODRIGUEZ, T. Estudio sobre la ciudad y el nomadismo en "Es viernes para siempre, Marilín"[En línea]. Noviembre 2011. [Consulta: 16 de diciembre de 2019]. Disponible en Pdf: http://ceilat.udenar.edu.co/wpcontent/uploads/2011/11/ESTUDIO-SOBRE-LA-CIUDAD_TANNIA-RODRIGUEZ.pdf.

RUALES, H. Historias de la ciudad prohibida. 1a edición. Quito: Libresa, 1997. 195 páginas. Colección Antares. ISBN: 9789978493243.

RUEDA, S. “Modelos de ciudad más sostenible. Estrategias para competir”. En: Jordi Borja, et al. (aut.). Ciudad para la sociedad del siglo XXI. Valencia: ICARO, 2001, p. 137-165. 
SASSEN, S. The global city: New York, London, Tokyo. 2ª edición. Princeton, New Jersey, Oxford: Princeton University Press, 2001. 447 páginas. ISBN: 9780691070636.

SANTOS, M. La naturaleza del espacio: técnica y tiempo, razón y emoción. María Laura Silveira (trad.). 1aㅗ edición. Barcelona: Ariel, 2000. 348 páginas. ISBN: 84-344-3460-1.

SENNETT, R. Construir y habitar. Ética para la ciudad. Marco Galmarini (trad.). 1ํㅗ edición. Barcelona: Anagrama, 2019. 464 páginas. Colección Argumentos. ISBN: 978-84-339-6433-5.

SHOER ROTH, D. "Si vas a extender tu estadía en Estados Unidos, acelera tu caso con nueva tecnología de USCIS" [En línea]. EI Nuevo Herald. 22 de mayo de 2019. https://www.elnuevoherald.com/noticias/finanzas/acceso-miami/asuntos-legales/article230705284.html [Consulta: 07 marzo 2020].

TORRES, A. "Lugar y vínculo social: concibiendo futuros". En: Peter Brand (edit.). La ciudad latinoamericana en el siglo XXI: globalización, neoliberalismo, planeación. Medellín: Universidad Nacional de Colombia, 2009, p. 197-218.

UNESCO. Creative Cities Network[en línea]: https://en.unesco.org/creative-cities/ [Consulta: 12 de diciembre de 2019].

VILANOVA, N. y ORTEGA, I. Generación Z. Todo lo que necesitas saber sobre los jóvenes que han dejado viejos a los millennials. 1a edición. Barcelona: Plataforma Editorial, 2017. 184 páginas. ISBN: 978-84-17114$32-9$.

\section{Bio}

Rubén Arturo Cacsire Grimaldos. Arquitecto, doctorando en el Programa de Comunicación Arquitectónica de la Escuela Técnica Superior de Arquitectura de la Universidad Politécnica de Madrid. Beca Presidente de la República del Programa Nacional de Becas y Crédito Educativo PRONABEC del Ministerio de Educación del Perú. Profesor Asociado de la Universidad Nacional del Altiplano, Coordinador de Investigación de la Escuela Profesional de Arquitectura y Urbanismo e Investigador en historia, arquitectura y patrimonio altiplánico y andino.

Rubén Arturo Cacsire Grimaldos. Architect, $\mathrm{PhD}$ student in the Architectural Communication Program of the Higher Technical School of Architecture in the Polytechnic University of Madrid. President of the Republic Scholarship of the National Program of Educational Scholarships and Credit PRONABEC of the Ministry of Education of Peru. Associate Professor of the National University of the Altiplano, Research Coordinator of the Professional School of Architecture and Urbanism and Researcher in history, architecture and highland Andean heritage.

Angelique Trachana. Doctora Arquitecta, profesora de la Escuela Técnica Superior de Arquitectura de la Universidad Politécnica de Madrid; miembro del Grupo de Investigación e Innovación Educativa Hypermedia; miembro de la Comisión Académica del Doctorado en Comunicación Arquitectónica. Ha ocupado puestos de responsabilidad en el Instituto Español de Arquitectura de la Universidad de Alcalá (UAH, 1995-2001), el Colegio Oficial de Arquitectos de Madrid (COAM, 1999-2008), el Instituto de Arquitectura del COAM ((2004-2008) y el Círculo de Bellas Artes de Madrid (2000-2001) donde ha desarrollado proyectos relacionados con la comunicación y la difusión de la cultura arquitectónica y de la ciudad, así como la Formación Continua de los Arquitectos. Editora de la revista Astrágalo. Cultura de la Arquitectura y la Ciudad (1995-2001). Ha publicado varios libros y artículos en revistas especializadas. Su investigación se centra en las nuevas tecnologías de la información y la comunicación enfocando los cambios que han implicado en la percepción y la concepción del espacio vivencial. 
Angelique Trachana. PhD Architect, professor at the Higher Technical School of Architecture of the Polytechnic University of Madrid; member of the Hypermedia Research and Educational Innovation Group; member of the Academic Commission of the Architectural Communication Doctorate Program She has held management positions at the Spanish Institute of Architecture in the University of Alcalá (UAH, 1995-2001), the Official College of Architects of Madrid (COAM, 1999-2008), the COAM Institute of Architecture ((2004-2008) and the Madrid Fine Arts Circle (2000-2001) where she has developed projects related to communication and the dissemination of the architecture and the city culture, as well as Continuous Training for the Architects. She was the editor of the magazine Astrágalo. Culture of Architecture and the City (1995-2001). She has published several books and articles in specialized magazines. Her research focuses on new information and communication technologies regarding the changes that have implied in the perception and conception of the experiential space. 